\title{
THE
}

\section{Decacationic Pillar[5]arene: A New Scaffold for the Development of 129Xe MRI Imaging Agents}

\author{
P. U. Ashvin I. Fernando \\ Yurii Shepelytskyi \\ Paul T. Cesana \\ University of Rhode Island, paul_cesana@my.uri.edu \\ Alanna Wade \\ Vira Grynko
}

See next page for additional authors

Follow this and additional works at: https://digitalcommons.uri.edu/chm_facpubs

Creative Commons License

(c) (i)

This work is licensed under a Creative Commons Attribution 4.0 License.

\section{Citation/Publisher Attribution}

Fernando, P. U. A. I., et al. (2020) Decacationic Pillar[5]arene: A New Scaffold for the Development of 129Xe MRI Imaging Agents. ACS Omega https://doi.org/10.1021/acsomega.0c02565

This Article is brought to you for free and open access by the Chemistry at DigitalCommons@URI. It has been accepted for inclusion in Chemistry Faculty Publications by an authorized administrator of DigitalCommons@URI. For more information, please contact digitalcommons-group@uri.edu. 


\section{Authors}

P. U. Ashvin I. Fernando, Yurii Shepelytskyi, Paul T. Cesana, Alanna Wade, Vira Grynko, Adriana M. Mendieta, Lauren E. Seveney, Joseph D. Brown, Francis T. Hane, Mitchell S. Albert, and Brenton DeBoef 


\title{
Decacationic Pillar[5]arene: A New Scaffold for the Development of ${ }^{129}$ Xe MRI Imaging Agents
}

\author{
P. U. Ashvin I. Fernando, Yurii Shepelytskyi, Paul T. Cesana, Alanna Wade, Vira Grynko, \\ Adriana M. Mendieta, Lauren E. Seveney, Joseph D. Brown, Francis T. Hane, Mitchell S. Albert, \\ and Brenton DeBoef*
}

Cite This: https://dx.doi.org/10.1021/acsomega.0c02565

Read Online

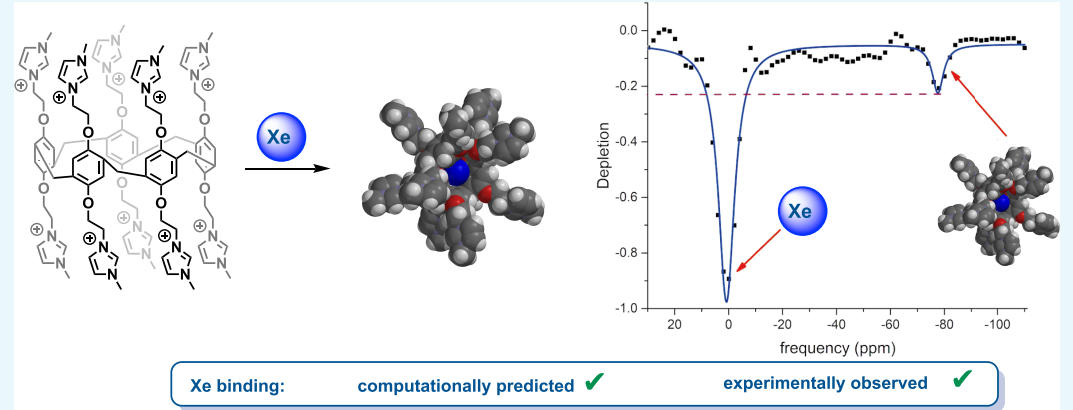

ABSTRACT: A decacationic water-soluble pillar[5] arene possessing a nonsolvated hydrophobic core has been designed and synthesized. This supramolecular host is capable of binding xenon, as evidenced by hyperCEST depletion experiments. Fluorescence-based studies also demonstrate that xenon binds into the cavity of the pillararene with an association constant of $4.6 \times$ $10^{3} \mathrm{M}^{-1}$. These data indicate that the water-soluble pillararene is a potential scaffold for building contrast agents that can be detected by xenon-129 magnetic resonance imaging.

\section{INTRODUCTION}

While the majority of the work in the field of ${ }^{129} \mathrm{Xe}$ magnetic resonance imaging (MRI) has focused on the development of targeted biosensors for molecular imaging applications, we propose that nontargeted ${ }^{129} \mathrm{Xe}$ MRI contrast agents could be a useful alternative to conventional metal-based contrast agents. ${ }^{1-3}$ Inhaled ${ }^{129} \mathrm{Xe}$ is nontoxic, readily distributes throughout the body, and can be easily detected using a conventional MRI instrument with a broadband receiver and coil. $^{4-7}$ Localized contrast can then be achieved by employing macrocyclic agents that reversibly bind ${ }^{129} \mathrm{Xe}$ in vivo. This reversible binding can then be selectively imaged via a saturation transfer pulse sequence, hyperCEST, thus providing a localized signal that can be transformed into a threedimensional image. ${ }^{2,3,8,9}$ Herein, we describe the development of a water-soluble xenon-binding macrocycle and its detection via hyperCEST in a clinical MRI instrument.

We have recently shown the first example of in vivo hyperCEST imaging using a nonfunctionalized biosensor, cucurbit[6] uril (CB6), which was injected into a rat prior to the imaging experiment. ${ }^{10}$ As previously described, the molecular host bound the inhaled ${ }^{129} \mathrm{Xe}$ in vivo, producing a ${ }^{129} \mathrm{Xe}$ magnetic resonance signal in the specific regions of the vasculature, corresponding to the biodistribution of CB6.
Despite the fact that numerous studies have shown CB6 to be nontoxic, it may not be the best candidate for biosensor development. Our previous findings showed that relatively high concentrations $(10 \mathrm{mM})$ of the agent were required for in vivo imaging. Additionally, CB6 may not be ideal as a nontargeted Xe contrast agent because it is known to bind a variety of small-molecule analytes, which may compete with Xe in vivo and complicate the interpretation of the imaging data. ${ }^{11}$

Cryptophanes have also been extensively studied for their ability to bind Xe; however, they are difficult to synthesize and functionalize. $^{12-15}$ The majority of the work in this field has focused on the development of targeted biosensors toward the goal of molecular imaging via ${ }^{129} \mathrm{Xe}$ MRI. A wide variety of binding studies have been performed and remarkable sensitivities have been reported, ${ }^{2}$ but cryptophane-based probes have yet to be used in vivo.

Received: May 30, 2020

Accepted: October 7, 2020 
Consequently, the key to the development of hyperCEST MRI contrast agents is the discovery of nontoxic, water-soluble Xe-binding scaffolds that can be readily synthesized and functionalized. The ideal molecular host for use in ${ }^{129} \mathrm{Xe}$ MRI would be easy to synthesize in large quantities, highly watersoluble, and would reversibly bind ${ }^{129} \mathrm{Xe}$, as evidenced by a hyperCEST experiment (Figure 1). ${ }^{16}$ Herein, we describe how

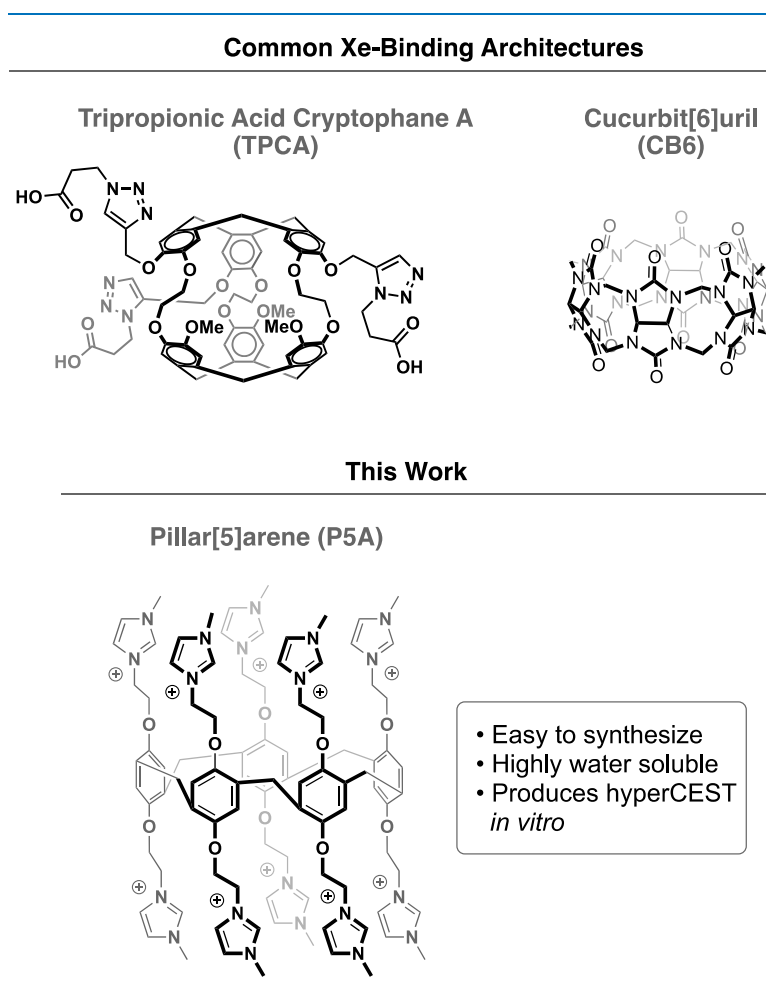

Figure 1. Comparison of Xe-binding hosts.

computational studies assisted in the design and synthesis of a new xenon-binding motif, which is the first step toward the development of a new class of potential ${ }^{129} \mathrm{Xe}$ contrast agents based on the pillar[5] arene macrocycle core.

Pillar[5] arenes (P5As) are pentameric macrocycles, synthesized by the templated Friedel-Crafts cyclization of hydroquinone derivatives. Since they were initially synthesized by Ogoshi a decade ago, ${ }^{17}$ P5As have been used for a wide range of applications in host-guest chemistry. ${ }^{18,19}$ P5As contain a central cavity of approximately $5.8 \AA^{3}$, which is comparable to other macrocycles that have been shown to have an affinity for $\mathrm{Xe}$, such as CB6 and cryptophane-A. In addition, both Cohen and Schröder have shown that P5A derivatives can interact with $\mathrm{Xe}$, as evidenced by conventional ${ }^{129} \mathrm{Xe}$ NMR and by magnetization transfer experiments. ${ }^{20,21}$ Herein, we report the development of a P5A structure that has been designed for its ability to bind xenon. We then quantify its affinity for the noble gas, and we show that the binding of Xe in the water-soluble pillararene can be detected via hyperCEST using a clinical MRI scanner, thus validating its potential as a contrast agent for ${ }^{129} \mathrm{Xe} \mathrm{MRI}$, and laying the necessary groundwork for subsequent in vivo imaging studies.

\section{RESULTS AND DISCUSSION}

We began our studies by computationally modeling a variety of P5A structures. Gas-phase energy minimized structures of pillararenes were obtained using semiempirical computations and a PM3 force field. A Xe atom was then placed outside the hydrophobic core of the P5A structure, and the energy of the system was minimized again to model the dynamics of the two species. Interestingly, the simplest P5A, which was decorated with 10 methyl groups (5), failed to bind $\mathrm{Xe}$ in this computational experiment. Additionally, P5A structures that were decorated with longer alkyl chains also failed to bind Xe (e.g., 2). In both of these cases, the molecular dynamics experiments showed that the alkyl arms of the P5A structures preferred to fold onto themselves via hydrophobic collapse. Contrastingly, the P5A structure containing 10 cationic imidazolium groups, which was first synthesized by Huang, ${ }^{22}$ opened like the petals of a flower, revealing the hydrophobic core. The aforementioned gas-phase molecular dynamics experiment predicted that this decacationic P5A should be an excellent candidate for binding xenon. Moreover, this highly charged compound was readily water soluble, making it an excellent candidate for a hyperCEST contrast agent (Scheme 1).

We further used molecular dynamics simulations in an aqueous environment to predict the binding and hydrophobicity of 3 . These simulations were performed using 1000 iterations with a 0.001 ps time step size for discretizing the equations of motion for unconstrained bond lengths, which allows free motion. The simulations were conducted in the presence of 1830 water molecules within a P1 type cell with $x$, $y$, and $z$ distances of 90,90 , and $90 \AA$ (Figure 2 ). There does not appear to be evidence that the highly charged 3 organizes water molecules on its surface, but it is clear that the interior cavity of macrocycle is highly hydrophobic. As before, the Xe atom was computationally placed outside the hydrophobic cavity of the P5A and was observed to rapidly associate with the hydrophobic core during the molecular dynamics simulation, thus indicating that the cationic P5A was capable of binding a single $\mathrm{Xe}$ atom in an aqueous solution. As shown in Figure 2, these computations predicted that the hydrophobic core of the P5A was not a good host for water molecules; thus, it was capable of binding a Xe atom with no desolvation cost. The neutral pillararenes, $\mathbf{2}$ and $\mathbf{5}$, contained similar hydrophobic cores that were capable of binding xenon, but these cores were not accessible to solvated xenon molecules because the molecule folded inward, as shown in Scheme 1 . Consequently, the ability of 3 to bind xenon was a result of both its appropriately sized hydrophobic pocket and the open aperture that was created by the cationic network on the rim of the hydrophobic core.

As previously shown in Scheme 1, the synthesis of the watersoluble P5A commenced with the Friedel-Crafts cyclization of 1,4-bis(2-bromoethoxy)benzene (1) in dichloroethane. This solvent is crucial for the synthesis of P5As because it serves as a template, allowing for high yields of the cyclic oligomer and preventing polymeric products. Subsequently, 10 imidazolium ions were added in a single step, and the decacationic pillararene was isolated by recrystallization from ethanol and diethyl ether. ${ }^{22}$

${ }^{1} \mathrm{H}$ NMR spectroscopy of the pillararenes confirmed the computationally predicted structures that were previously shown (Figure 3). The decabromo-P5A (2) was characterized by sharp peaks in the ${ }^{1} \mathrm{H}$ NMR spectrum, indicating that its structure was rigid and compact, whereas the ${ }^{1} \mathrm{H}$ NMR spectrum of the decacationic P5A (3) contained broad peaks. Heating the sample did not change the spectrum, so we 
Scheme 1. Synthesis and Computed Structures of Neutral and Decacationic Pillararenes
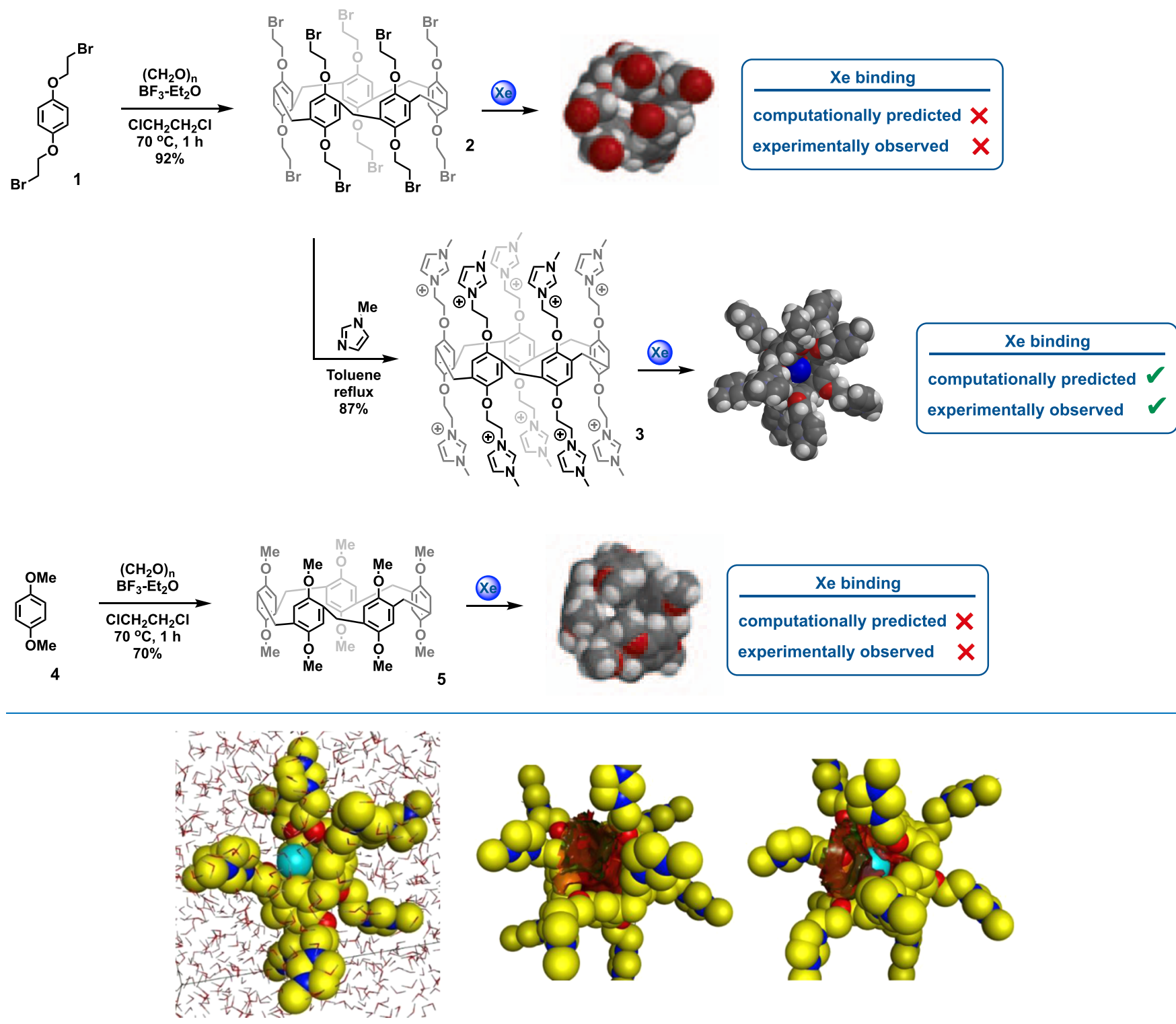

Figure 2. L to R: Molecular dynamics simulations of Xe and 3 using 1,830 water molecules; computed hydrophobic surface of 3 is shown in red; Xe binds to the hydrophobic surface of 3 .

concluded that the peak broadening was not the result of molecular flexibility.

Further inspection by dynamic light scattering (DLS) indicated that 3 forms $6-10 \mathrm{~nm}$ clusters (see the Supporting Information) in the aqueous solution. Similar nanoscale assemblies have been observed for water-soluble cryptophanes; importantly, the clustering in that case did not preclude the host's ability to serve as a biosensor in in vitro assays. ${ }^{15}$ DLS in experiments with 3 in the presence and absence of xenon showed that the clusters remained intact even in the presence of the guest molecule.

The formation of P5A-based nanoclusters could also be advantageous for the development of the nontargeted Xe-based contrast agent that we envision. Iron-based nanoparticles of similar size have been shown to be clinically viable contrast agents, $^{23}$ and previous studies have shown that loading multiple Xe-binding cryptophanes onto a nanostructure is an effective method for increasing the sensitivity of a HyperCEST probe. $^{24}$ Analogously, the development of porous, watersoluble organic nanoparticles based on 3 could be advantageous as a Xe-binding contrast agent.

The ability of the cationic pillararene nanoparticles to bind Xe was confirmed by fluorescence quenching experiments. P5As are weakly fluorescent due to cross-conjugation interactions between the rigidified benzene rings, and titration of an aqueous solution of $\mathrm{Xe}$ into a solution of 3 induced quenching via an external spin-orbit coupling mechanism (Figure 4, See the Supporting Information for experimental details). ${ }^{25,26}$ The data from the fluorescence quenching experiments show a maximum occupancy of one $\mathrm{Xe}$ atom per P5A host. A nonlinear curve fitting method for single-site binding was used to calculate the association constant $\left(K_{\mathrm{a}}\right){ }^{27}$

Dmochowski has performed similar fluorescence quenching studies for measuring the affinity of $\mathrm{Xe}$ for the water-soluble cryptophane shown in Figure $1,{ }^{13}$ reporting an $K_{\mathrm{a}}$ of $1.7 \times 10^{4}$ $\mathrm{M}^{-1}$. The association constant for Xe binding to 3 was 1 order 


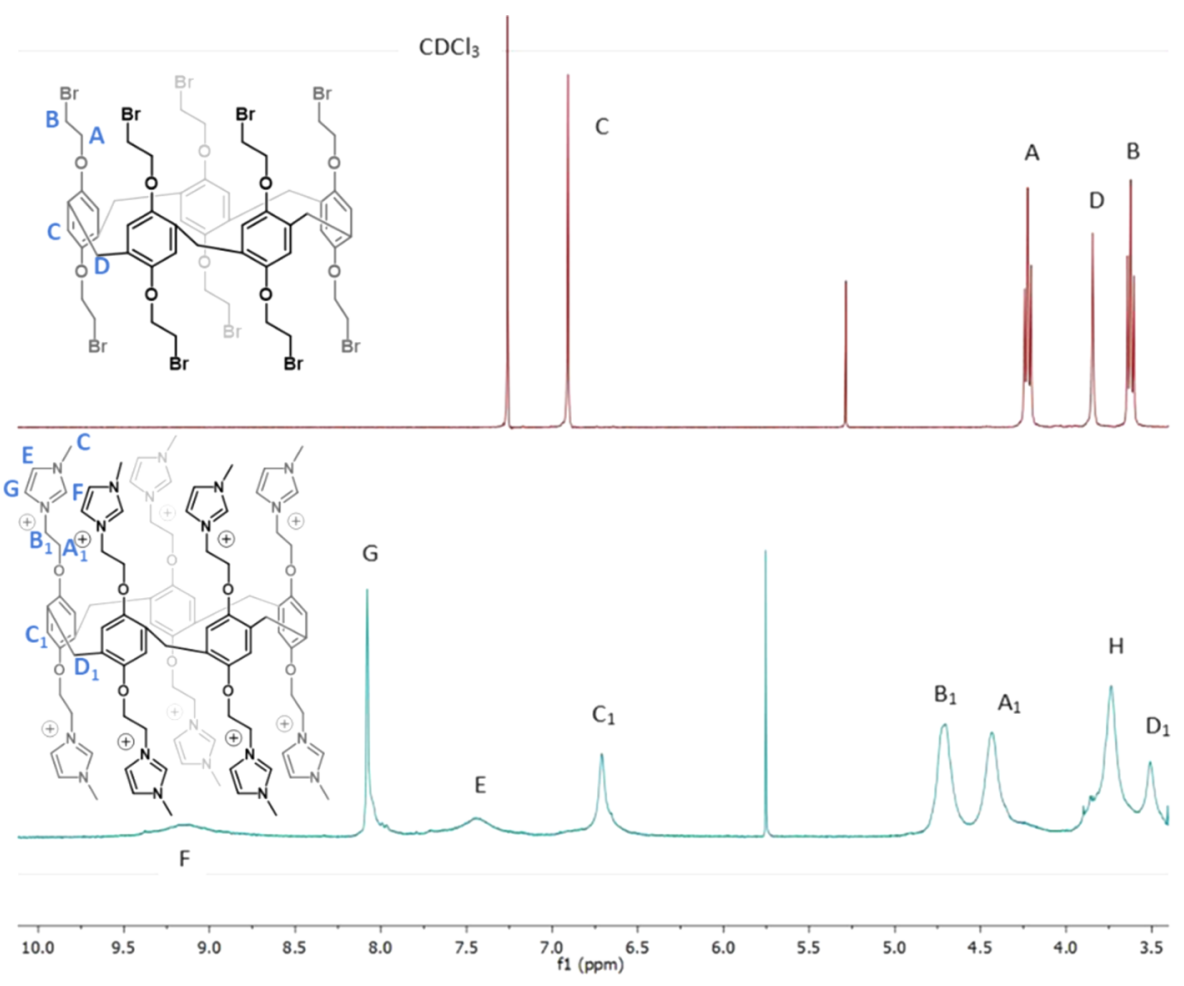

Figure 3. ${ }^{1} \mathrm{H}$ NMR spectra of 2 in $\mathrm{CDCl}_{3}$ (top) and 3 in DMSO- $d_{6}$ (bottom). Product peaks are assigned.

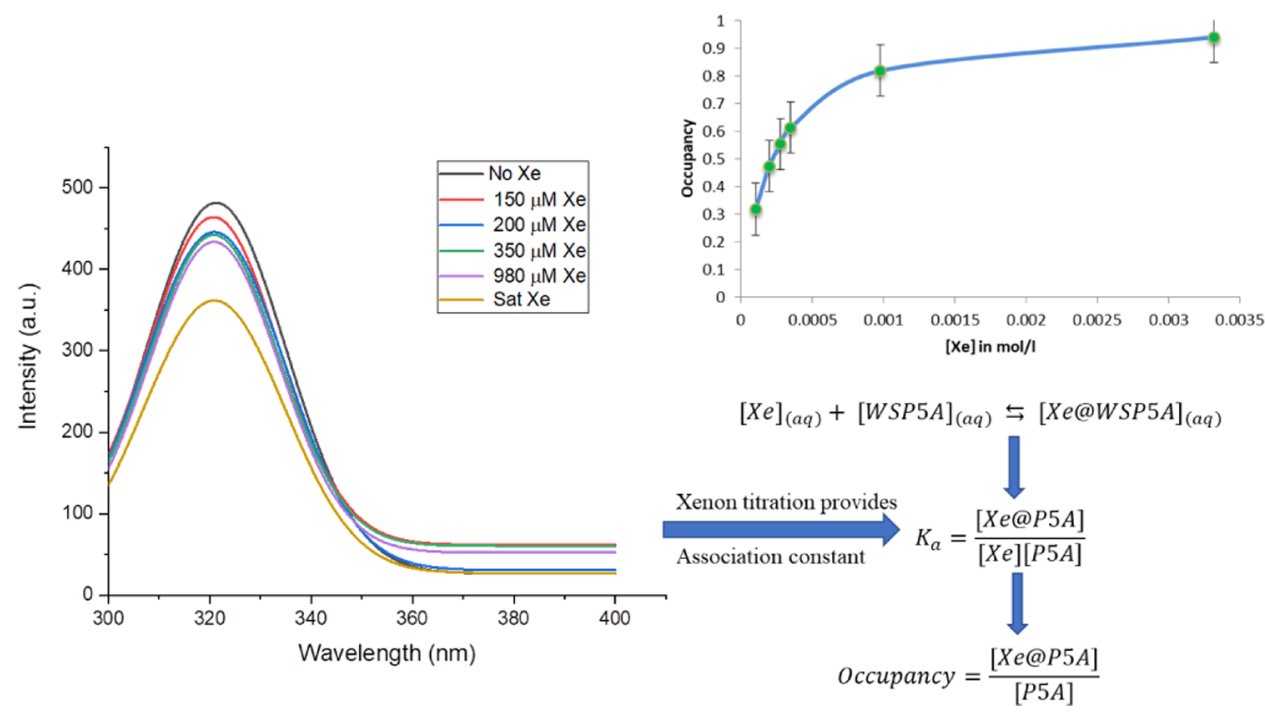

Figure 4. Fluorescence quenching phenomena when Xe (aq) added into a solution of 3 (aq) in phosphate buffer (left). Occupancy curve with respect to the concentration of $\mathrm{Xe}_{(\mathrm{aq})}$ (right).

of magnitude lower, $4.6 \times 10^{3} \mathrm{M}^{-1}$. It should be noted that potential biosensors or contrast agents do not need to bind $\mathrm{Xe}$ with high affinity because the hyperCEST experiment capitalizes on the reversible binding of Xe in a supramolecular host. Finally, the potential application of 3 as a ${ }^{129} \mathrm{Xe}$ MRI contrast agent was assessed. The z-spectrum of an aqueous solution of 3 was acquired using 16 sinusoidal saturation pulses and a $2 \mathrm{ppm}$ frequency-changing step (Figure 5). The characteristic peak at $-77 \mathrm{ppm}$ corresponds to the key ${ }^{129} \mathrm{Xe} @ 3$ complex. This is approximately $10 \mathrm{ppm}$ upfield compared to the cucurbit[6]uril (CB6) peak position. Although the depletion was $23 \%$, which is approximately 2.7 times smaller than CB6, ${ }^{10}$ a $23 \%$ hyperCEST is sufficient for imaging studies. ${ }^{28}$ It is also likely that this result could be improved by modifying the prepulse train parameters, which should allow for better depolarization of the encapsulated Xe. Importantly, these hyperCEST experiments were acquired with a Phillips Achieva 3T MRI scanner, indicating that this technology can likely be translated for preclinical and clinical imaging studies.

As previously mentioned, computations predicted that in aqueous media, the decamethyl-P5A, 5, and the brominated P5A derivative, 2, would undergo hydrophobic collapse, folding into themselves and preventing the binding of Xe. This could not be directly tested experimentally because 2 and $\mathbf{5}$ are not water soluble; however, the solutions of $\mathbf{2}$ and $\mathbf{5}$ in 
a

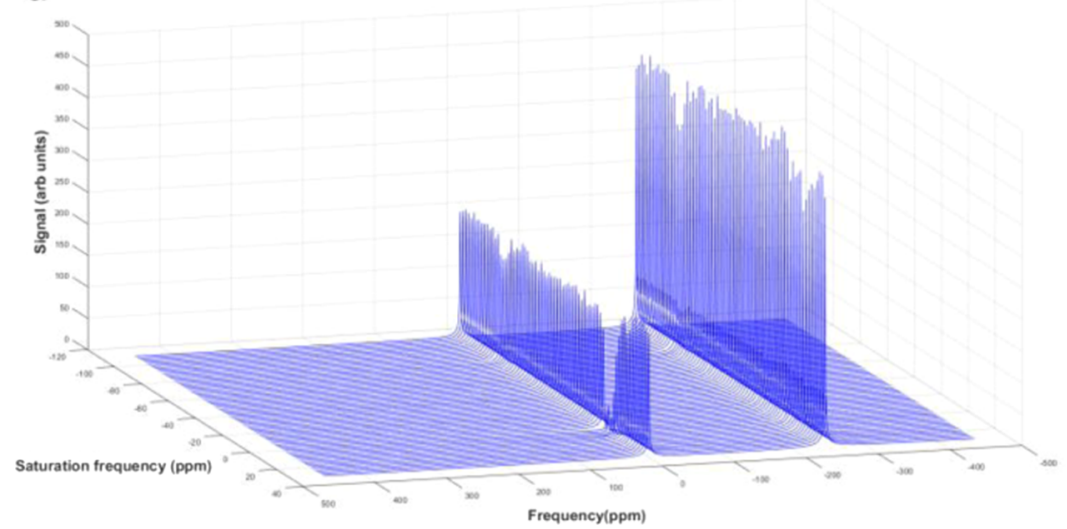

b

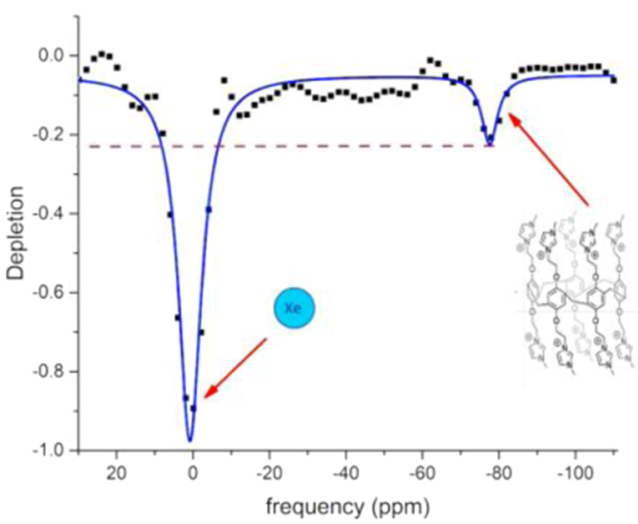

Figure 5. Acquired ${ }^{129} \mathrm{Xe}$ MRS spectra at $3 \mathrm{~T}$ acquired at different saturation frequencies (a). Dissolved phase corresponds to 0 ppm. HyperCEST depletion spectrum for ${ }^{129} \mathrm{Xe}$ binding in water-soluble pillar[5] arene (b). Lorentzian fit is shown as a solid blue line.

both pure dimethyl sulfoxide (DMSO) and water/DMSO mixtures did not show hyperCEST.

\section{CONCLUSIONS}

We have successfully designed and synthesized a water-soluble pillar[5] arene that is capable of forming a 1:1 complex with Xe, and we have characterized its affinity for $\mathrm{Xe}$ by both fluorescence quenching titrations and hyperCEST. This new xenon host could find application as a ${ }^{129} \mathrm{Xe}$ MRI contrast agent or targeted biosensor due to its ability to reversibly bind xenon in an aqueous solution. Since the hyperCEST imaging technique capitalizes on the reversible binding of xenon by a macrocylic host, a balance of thermodynamic and kinetic properties are desirable: tight binding will not allow for the rapid exchange of the xenon atoms, but too weak of binding will not allow for sufficient depolarization by the hyperCEST pulse. It appears that 3 achieves this balance by having a nonsolvated hydrophobic core that binds the xenon and wide apertures on either side of the core that allows for facile chemical exchange.

Subsequent efforts in our laboratories will be dedicated to assessing the toxicity of macrocycles, like 3 , and then employing them in in vivo imaging studies. While it is true that polycationic compounds have been shown to be toxic, compounds containing multiple cationic residues have also been shown to be effective antibiotics. ${ }^{26,27}$ In general, the toxicity of polycationic compounds increases with molecular weight, ${ }^{28}$ so there is reason to believe that 3 may be considerably less toxic than the polycationic polymers that are currently used as gene delivery agents. ${ }^{29}$

Both this study and our previous work has shown that the remarkable pM-level sensitivities that have been reported for xenon-binding hosts in high-field NMR spectrometers do not directly translate to clinical instrumentation, where only $\mathrm{mM}$ concentrations can be observed. ${ }^{10,30}$ In general, pillar[5]arenes bind linear hydrophobic molecules, like alkanes. While it is possible that greasy endogenous molecules could complete with xenon for binding to 3 , it is also likely that the compounds that bind 3 will be different than those that bind to CB6, so the two hosts could be compliments to each other. Consequently, we will continue to develop applications of Xe-binding molecular hosts, like 3, for use as both targeted and nontargeted ${ }^{129}$ Xe MRI contrast agents.

\section{ASSOCIATED CONTENT}

\section{(s) Supporting Information}

The Supporting Information is available free of charge at https://pubs.acs.org/doi/10.1021/acsomega.0c02565.

Synthetic procedures, ${ }^{1} \mathrm{H}$ and ${ }^{13} \mathrm{C}$ NMR spectra, and experimental information for ${ }^{129} \mathrm{Xe}$ NMR and fluorescence binding studies (PDF)

\section{AUTHOR INFORMATION}

\section{Corresponding Author}

Brenton DeBoef - Department of Chemistry, University of Rhode Island, Kingston, Rhode Island 02881, United States; ๑ orcid.org/0000-0002-9270-2557; Email: bdeboef@ chm.uri.edu

\section{Authors}

P. U. Ashvin I. Fernando - Department of Chemistry, University of Rhode Island, Kingston, Rhode Island 02881, United States; U.S. Army Corps of Engineers, Engineer Research and Development Center, Vicksburg, Mississippi 39180, United States

Yurii Shepelytskyi - Department of Chemistry, Lakehead University, Thunder Bay, Ontario P7B 6V4, Canada; ๑ orcid.org/0000-0001-5526-7958

Paul T. Cesana - Department of Chemistry, University of Rhode Island, Kingston, Rhode Island 02881, United States

Alanna Wade - Department of Chemistry, Lakehead University, Thunder Bay, Ontario P7B 6V4, Canada

Vira Grynko - Department of Chemistry, Lakehead University, Thunder Bay, Ontario P7B 6V4, Canada

Adriana M. Mendieta - Department of Chemistry, University of Rhode Island, Kingston, Rhode Island 02881, United States

Lauren E. Seveney - Department of Chemistry, University of Rhode Island, Kingston, Rhode Island 02881, United States

Joseph D. Brown - Department of Chemistry, University of Rhode Island, Kingston, Rhode Island 02881, United States; United States Coast Guard Academy, New London, Connecticut 06320, United States

Francis T. Hane - Thunder Bay Regional Research Institute, Thunder Bay, Ontario P7B 6V4, Canada

Mitchell S. Albert - Department of Chemistry, Lakehead University, Thunder Bay, Ontario P7B 6V4, Canada; Thunder Bay Regional Research Institute, Thunder Bay, Ontario P7B 6V4, Canada 
Complete contact information is available at:

https://pubs.acs.org/10.1021/acsomega.0c02565

\section{Author Contributions}

The team at the University of Rhode Island (P.U.A.I.F., P.T.C., A.M.M., L.E.S., J.D.B., and B.D.B.) designed and performed the computations, synthesis, dynamic light scattering, and fluorescence binding experiments. The team in Thunder Bay, Canada (Y.S., A.W., V.G., F.T.H., and M.S.A.) acquired the zspectrum using hyperpolarized xenon-129 and interpreted the data. P.U.A.I.F. and B.D.B. wrote the manuscript with input from all of the co-authors.

\section{Funding}

F.T.H. wishes to acknowledge the BrightFocus Foundation and its generous donors for support of this work. Y.S. was funded by an Ontario Graduate Scholarship and Mitacs Accelerate Grant (IT10555). V.G. was supported by an Ontario Trillium Scholarship. Portions of this work were supported by a Natural Science Engineering Research Council Discovery grant (M.S.A., 11-50-16090121).

\section{Notes}

The authors declare no competing financial interest.

\section{ACKNOWLEDGMENTS}

P.U.A.I.F. and B.D.B. thank Bill Euler for insightful discussions and experimental assistance.

\section{REFERENCES}

(1) Schröder, L. Xenon Biosensor HyperCEST MRI, In Hyperpolarized and Inert Gas MRI, Albert, M. S.; Hane, F. T., Eds.; Academic Press: New York, 2016; pp 263-277.

(2) Schröder, L. Xenon for NMR biosensing-inert but alert. Phys. Med. 2013, 29, 3-16.

(3) Wang, Y.; Dmochowski, I. J. An Expanded Palette of Xenon-129 NMR Biosensors. Acc. Chem. Res. 2016, 49, 2179-2187.

(4) Albert, M. S.; Cates, G. D.; Driehuys, B.; Happer, W.; Saam, B.; Springer, C. S., Jr; Wishnia, A. Biological magnetic resonance imaging using laser-polarized ${ }^{129}$ Xe. Nature 1994, 370, 199-201.

(5) Albert, M. S.; Schepkin, V. D.; Budinger, T. F. Measurement of ${ }^{129} \mathrm{Xe} \mathrm{T} 1 \mathrm{in}$ blood to explore the feasibility of hyperpolarized ${ }^{129} \mathrm{Xe}$ MRI. J. Comput. Assist. Tomogr. 1995, 19, 975-978.

(6) Chahal, S.; Prete, B. R. J.; Wade, A.; Hane, F. T.; Albert, M. S. Brain Imaging Using Hyperpolarized ${ }^{129} \mathrm{Xe}$ Magnetic Resonance Imaging. Methods Enzymol. 2018, 603, 1-16.

(7) Zhou, X.; Sun, Y.; Mazzanti, M.; Henninger, N.; Mansour, J.; Fisher, M.; Albert, M. MRI of Stroke Using Hyperpolarized 129Xe. NMR Biomed. 2011, 24, 170-175.

(8) Schröder, L.; Lowery, T. J.; Hilty, C.; Wemmer, D. E.; Pines, A. Molecular imaging using a targeted magnetic resonance hyperpolarized biosensor. Science 2006, 314, 446-449.

(9) Berthault, P.; Huber, G.; Desvaux, H. Biosensing using laserpolarized xenon NMR/MRI. Prog. Nucl. Magn. Reson. Spectrosc. 2009, $55,35-60$.

(10) Hane, F. T.; Tao, L.; Smylie, P.; Pellizzari, R. M.; Plata, J. A.; DeBoef, B.; Albert, M. S. In vivo detection of cucurbit[6]uril, a hyperpolarized xenon contrast agent for a xenon magnetic resonance imaging biosensor. Sci. Rep. 2017, 7, No. 41027.

(11) Assaf, K. I.; Nau, W. M. Cucurbiturils: from synthesis to highaffinity binding and catalysis. Chem. Soc. Rev. 2014, 44, 394-418.

(12) Hill, P. A.; Wei, Q.; Troxler, T.; Dmochowski, I. J. Substituent Effects on Xenon Binding Affinity and Solution Behavior of WaterSoluble Cryptophanes. J. Am. Chem. Soc. 2009, 131, 3069-3077.

(13) Hill, P. A.; Wei, Q.; Eckenhoff, R. G.; Dmochowski, I. J. Thermodynamics of Xenon Binding to Cryptophane in Water and Human Plasma. J. Am. Chem. Soc. 2007, 129, 9262-9263.
(14) Bai, Y.; Hill, P. A.; Dmochowski, I. J. Utilizing a Water-Soluble Cryptophane with Fast Xenon Exchange Rates for Picomolar Sensitivity NMR Measurements. Anal. Chem. 2012, 84, 9935-9941.

(15) Zemerov, S. D.; Roose, B. W.; Greenberg, M. L.; Wang, Y.; Dmochowski, I. J. Cryptophane Nanoscale Assemblies Expand ${ }^{129} \mathrm{Xe}$ NMR Biosensing. Anal. Chem. 2018, 90, 7730-7738.

(16) Hane, F. T.; Fernando, A.; Prete, B. R. J.; Peloquin, B.; Karas, S.; Chaudhuri, S.; Chahal, S.; Shepelytskyi, Y.; Wade, A.; Tao, L.; DeBoef, B.; Albert, M. S. Cyclodextrin-Based Pseudorotaxanes: Easily Conjugatable Scaffolds for Synthesizing Hyperpolarized Xenon-129 Magnetic Resonance Imaging Agents. ACS Omega 2018, 3, 677-681.

(17) Ogoshi, T.; Kanai, S.; Fujinami, S.; Yamagishi, T.-A.; Nakamoto, Y. para-Bridged Symmetrical Pillar[5]arenes: Their Lewis Acid Catalyzed Synthesis and Host-Guest Property. J. Am. Chem. Soc. 2008, 130, 5022-5023.

(18) Xue, M.; Yang, Y.; Chi, X.; Zhang, Z.; Huang, F.; Pillararenes, A. New Class of Macrocycles for Supramolecular Chemistry. Acc. Chem. Res. 2012, 45, 1294-1308.

(19) Ogoshi, T.; Yamagishi, T.-A.; Nakamoto, Y. Pillar-Shaped Macrocyclic Hosts Pillar[n]arenes: New Key Players for Supramolecular Chemistry. Chem. Rev. 2016, 116, 7937-8002.

(20) Adiri, T.; Marciano, D.; Cohen, Y. Potential ${ }^{129}$ Xe-NMR biosensors based on secondary and tertiary complexes of a watersoluble pillar[5] arene derivative. Chem. Commun. 2013, 49, 70827084.

(21) Schnurr, M.; Joseph, R.; Naugolny-Keisar, A.; Kaizerman-Kane, D.; Bogdanoff, N.; Schuenke, P.; Cohen, Y.; Schröder, L. High Exchange Rate Complexes of ${ }^{129} \mathrm{Xe}$ with Water-Soluble Pillar[5]arenes for Adjustable Magnetization Transfer MRI. ChemPhysChem 2019, 20, 246-251.

(22) Yao, Y.; Xue, M.; Chi, X.; Ma, Y.; He, J.; Albiz, Z.; Huang, F. A new water-soluble pillar[5] arene: synthesis and application in the preparation of gold nanoparticles. Chem. Commun. 2012, 48, 65056507.

(23) Shen, Z.; Wu, A.; Chen, X. Iron Oxide Nanoparticle Based Contrast Agents for Magnetic Resonance Imaging. Mol. Pharm. 2017, 14, 1352-1364.

(24) Palaniappan, K. K.; Ramirez, R. M.; Bajaj, V. S.; Wemmer, D. E.; Pines, A.; Francis, M. B. Molecular imaging of cancer cells using a bacteriophage-based ${ }^{129} \mathrm{Xe}$ NMR biosensor. Angew. Chem., Int. Ed. 2013, 52, 4849-4853.

(25) Martinho, J. M. G. Heavy-atom quenching of monomer and excimer pyrene fluorescence. J. Phys. Chem. A 1989, 93, 6687-6692.

(26) Ding, B.; Yin, N.; Liu, Y.; Cardenas-Garcia, J.; Evanson, R.; Orsak, T.; Fan, M.; Turin, G.; Savage, P. B. Origins of Cell Selectivity of Cationic Steroid Antibiotics. J. Am. Chem. Soc. 2004, 126, 1364213648.

(27) Bergstrom, B. E.; Abdelkhalek, A.; Younis, W.; Hammac, K.; Townshend, W. M.; Seleem, M. N. Antibacterial activity and safety of commercial veterinary cationic steroid antibiotics and neutral superoxidized water. PLoS One. 2018, 13, e0193217-13.

(28) Monnery, B. D.; Wright, M.; Cavill, R.; Hoogenboom, R.; Shaunak, S.; Steinke, J. H. G.; Thanou, M. Cytotoxicity of polycations: Relationship of molecular weight and the hydrolytic theory of the mechanism of toxicity. Int. J. Pharm. 2017, 521, 249258.

(29) Lv, H.; Zhang, S.; Wang, B.; Cui, S.; Yan, J. Toxicity of cationic lipids and cationic polymers in gene delivery. J. Controlled Release. 2006, 114, 100-109.

(30) Hane, F. T.; Smylie, P. S.; Li, T.; Ruberto, J.; Dowhos, K.; Ball, I.; Tomanek, B.; DeBoef, B.; Albert, M. S. HyperCEST detection of cucurbit[6]uril in whole blood using an ultrashort saturation Prepulse train. Contrast Media Mol. Imaging 2016, 11, 285-290. 